\section{Commentary: Gastroesophageal reflux and lung allograft dysfunction: Need to improve detection and clinical reporting}

\author{
Usman Ahmad, MD, ${ }^{\mathrm{a}}$ and Charles R. Lane, $\mathrm{MD}^{\mathrm{b}}$
}

Etiologies and mechanisms that result in chronic lung allograft dysfunction have been relatively elusive. Among the many potential inciting events that directly or indirectly lead to chronic lung allograft dysfunction, gastroesophageal reflux disease (GERD) is a well-known risk factor. Although the relationship between GERD and lung dysfunction may be somewhat intuitive, the exact mechanism by which gastric contents incite pulmonary inflammation is not well established and assumes aspiration of refluxed contents.

There are little data that show directly measured or recorded refluxed contents in the lungs and their downstream correlation with native or allograft dysfunction. Measurement of gastric contents in bronchoalveolar lavage (BAL) is an imperfect science, and the study of GERD in lung dysfunction has been limited by the lack of a reliable and reproducible indicator of GERD in BAL. ${ }^{1-3}$ In fact, most of the evidence that implicates GERD in native or allograft lung dysfunction is indirect and comes from clinical series that study GERD and preventive effect of antireflux interventions. ${ }^{4-6}$

Antireflux procedures have been shown to stabilize decline in native lung function in patients with pulmonary fibrosis. ${ }^{7}$ These findings have also given credibility to the theory of GERD as an underlying etiology for pulmonary fibrosis. Likewise, antireflux procedures in lung transplant recipients with GERD have been shown to prevent allograft dysfunction, without any data clearly showing decrease in aspirated levels of gastric contents. Our understanding of

From the a Department of Cardiothoracic Surgery, Heart and Vascular Institute, Cleveland Clinic, Cleveland, Ohio; and ${ }^{\mathrm{b}}$ Department of Pulmonary Medicine, Respiratory Institute, Cleveland Clinic, Cleveland, Ohio.

Disclosures: Authors have nothing to disclose with regard to commercial support.

Received for publication Jan 1, 2020; revisions received Jan 1, 2020; accepted for publication Jan 2, 2020; available ahead of print Jan 22, 2020.

Address for reprints: Usman Ahmad, MD, Department of Cardiothoracic Surgery, Heart and Vascular Institute, Cleveland Clinic, Cleveland, OH 44195 (E-mail: ahmadu@ccf.org).

J Thorac Cardiovasc Surg 2020;160:868-9

$0022-5223 / \$ 36.00$

Copyright (c) 2020 by The American Association for Thoracic Surgery

https://doi.org/10.1016/j.jtcvs.2020.01.006

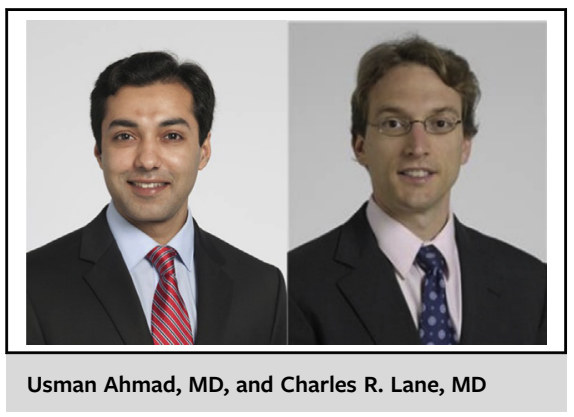

CENTRAL MESSAGE

GERD can be multifactorial and

needs to be studied in the

context of esophageal and

gastric motility disorders that are

common after lung transplanta-

tion. In addition, identification of

biochemical markers of gastric

content aspiration in BAL fluid

will help in the study of reflux and

measuring efficacy of its

treatment.

how severity of GERD as opposed to presence of GERD affects lung function is also limited. Although we assume that decrease in distal esophageal acid exposure time after antireflux surgery decreases aspiration of gastric contents, there is little direct proof of this.

What complicates matters even more is the fact that GERD after lung transplantation is a result of complex interactions between esophageal motility or lack thereof, gastroparesis and changes in gastroesophageal junction anatomy, and pressure gradients due to changes in thoracoabdominal pressure. Treating all patients with similar antireflux surgery without taking into account some of these other competing factors is rather simplistic and leads to more problems. For example, the mechanism for post-transplant GERD might be different in a patient with normal gastric emptying compared with one with gastroparesis (noted in up to $90 \%$ of lung transplant recipients). ${ }^{8}$ Therefore, the antireflux intervention should be modified accordingly. Likewise, antireflux interventions in the setting of esophageal dysmotility should accommodate for the lack of normal peristalsis.

By the same token, the results of antireflux interventions should be reported in the context of these concomitant esophageal or gastric motility problems. However, that 
has not been the case in the majority of published literature on the subject and thus limits its applicability and reproducibility. In the present article by Davidson and colleagues, ${ }^{9}$ the authors have amassed available data correlating antireflux surgery with preservation of allograft function. As expected, although they were able to confirm the beneficial effect of antireflux surgery, the available data were extremely variable and did not provide any of the above-mentioned context.

To make progress in the study of GERD and its effect on native or allograft lung dysfunction, we have to address the 2 major limitations discussed: (1) We need a reproducible marker of gastric contents that can be measured in BAL; and (2) we need to report GERD and antireflux procedure outcomes in the context of the organ proximal to the gastroesophageal junction and the one distal to it and not be oblivious to their dysfunction.

\section{References}

1. Parikh S, Brownlee IA, Robertson AG, Manning NT, Johnson GE, Brodlie M, et al. Are the enzymatic methods currently being used to measure bronchoalveolar lavage bile salt levels fit for purpose? J Heart Lung Transplant. 2013;32: 418-23.
2. Neujahr DC, Uppal K, Force SD, Fernandez F, Lawrence C, Pickens A, et al Bile acid aspiration associated with lung chemical profile linked to other biomarkers of injury after lung transplantation. Am J Transplant. 2014;14: 841-8.

3. Reder NP, Davis CS, Kovacs EJ, Fisichella PM. The diagnostic value of gastroesophageal reflux disease (GERD) symptoms and detection of pepsin and bile acids in bronchoalveolar lavage fluid and exhaled breath condensate for identifying lung transplantation patients with GERD-induced aspiration. Surg Endosc. 2014;28:1794-800

4. Griffin SM, Robertson AG, Bredenoord AJ, Brownlee IA, Stovold R, Brodlie M, et al. Aspiration and allograft injury secondary to gastroesophageal reflux occur in the immediate post-lung transplantation period (prospective clinical trial). Ann Surg. 2013;258:705-11.

5. Murthy SC, Nowicki ER, Mason DP, Budev MM, Nunez AI, Thuita L, et al. Pretransplant gastroesophageal reflux compromises early outcomes after lung transplantation. J Thorac Cardiovasc Surg. 2011;142:47-52.e3.

6. Davis RD Jr, Lau CL, Eubanks S, Messier RH, Hadjiliadis D, Steele MP, et al. Improved lung allograft function after fundoplication in patients with gastroesophageal reflux disease undergoing lung transplantation. J Thorac Cardiovasc Surg. 2003; 125:533-42

7. Raghu G, Pellegrini CA, Yow E, Flaherty KR, Meyer K, Noth I, et al. Laparoscopic anti-reflux surgery for the treatment of idiopathic pulmonary fibrosis (WRAP-IPF): a multicentre, randomised, controlled phase 2 trial. Lancet Respir Med. 2018;6:707-14.

8. Bodet-Milin C, Querellou S, Oudoux A, Haloun A, Horeau-Llanglard D, Carlier T, et al. Delayed gastric emptying scintigraphy in cystic fibrosis patients before and after lung transplantation. J Heart Lung Transplant. 2006;25:1077-83.

9. Davidson JR, Kumar S, Franklin D, Eaton S, Curry J, De Coppi P, et al Fundoplication to preserve allograft function after lung transplant: systematic review and meta-analysis. J Thorac Cardiovasc Surg. 2020;160:858-66.

\section{Commentary: The burning questions of reflux management in lung transplantation}

Hai Salfity, MD, MPH, and Matthew Hartwig, MD

Our knowledge of the complex mechanisms leading to chronic allograft rejection after lung transplantation is evolving. Early studies indicated non-alloimmune injury such as gastroesophageal reflux disease (GERD) poses risk by potentiating inflammation in the small airways

\footnotetext{
From the Department of Surgery, Duke University School of Medicine, Durham, NC. Disclosures: Authors have nothing to disclose with regard to commercial support. Received for publication Jan 25, 2020; accepted for publication Jan 26, 2020; available ahead of print Feb 7, 2020.

Address for reprints: Matthew Hartwig, MD, Department of Surgery, Duke University School of Medicine, DUMC Box 3863 Med Ctr, Durham, NC 27710 (E-mail: Matthew.hartwig@duke.edu).

J Thorac Cardiovasc Surg 2020;160:869-70 $0022-5223 / \$ 36.00$

Copyright (c) 2020 by The American Association for Thoracic Surgery

https://doi.org/10.1016/j.jtcvs.2020.01.071
}

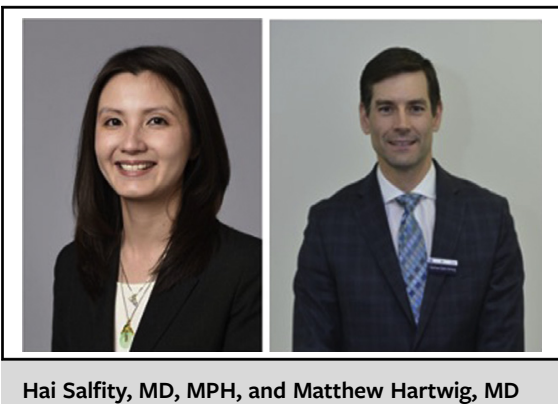

CENTRAL MESSAGE

Surgical management of gastroesophageal reflux disease may prolong allograft function in lung transplant patients. 